\title{
MYTH AND TECHNOLOGY: FINDING PHILOSOPHY'S ROLE IN TECHNOLOGICAL CHANGE
}

\author{
KIERAN BRAYFORD
}

\begin{abstract}
In this paper, I argue that philosophy's potential to influence technological change is impeded by the presence of two common and influential myths surrounding technology-the myth of progress and the myth of technological determinism. Such myths, I suggest, hinder philosophy's influence by presenting a distorted image of technology-respectively, as an unqualified good, and as an entity with its own autonomous logic. Steven Pinker and Martin Heidegger are selected as influential advocates for progress and technological determinism respectively, and their work is explored in turn. The work of John Gray and of Herbert Marcuse is then employed to demythologise technology by articulating an alternative image of technology that is not just more accurate, but also more conducive to philosophical influence. Finally, the work of Hans Jonas and Luciano Floridi is used to ground the conclusion that, should philosophy wish to influence technological change, an effective method of doing so could be the articulation of ethical maxims and the supervision of their translation into a real world setting.
\end{abstract}

Key words: ethics of technology; demythologisation; Steven Pinker; Herbert Marcuse; Luciano Floridi; technological determinism; progress.

This paper identifies and explores two philosophical myths that inhibit philosophy's potential influence over technological development—progress and technological determinism-before then offering a suggestion as to how philosophy's potential influence may best be achieved. I begin with Steven Pinker's suggestion that technological progress has been a significant factor in increased human wellbeing before then suggesting that this encourages an overly optimistic disposition towards technology. I then highlight a flaw in Pinker's thesis, and borrow examples from John Gray to undermine the purported link between technology and wellbeing. I then explore the myth of technological determinism, and its presentation of influence over technological development as impossible, drawing upon Martin Heidegger's famous critique of technology as an example of such thinking. I then draw upon Herbert Marcuse's critique of Heidegger to offer a rebuttal to the position and present an image of technology with societal influence at its core. Finally, I draw upon the work of Hans Jonas and Luciano Floridi to offer a suggestion as to how philosophy may best realise its influence over technological development. 


\section{Progress as a barrier to influence}

The idea of progress hinders philosophy from realising its potential to influence technological change. Though originally an Enlightenment ideal, progress has contemporary defenders, notably Steven Pinker. Pinker advances an image of the Enlightenment that consists of four overarching themes- "reason, science, humanism and progress" (Pinker, 2018, p. 8) - that each interact with one another to bring about positive changes to the human condition. According to Pinker, science increases our understanding of the world, and this, when combined with reason and a liberal cosmopolitan humanism, allows us to "make intellectual and moral progress" (2018, p. 11).

Technology, according to Pinker, plays two important roles in the aforementioned intellectual and moral progress. Firstly, there are those technologies that enable the recording and distribution of humanity's knowledge base- "writing, printing and electronic media" (2018, p. 233) are all exemplars of such technologies. These communications technologies, for Pinker, have a dual impact on human wellbeing. Their direct impact is felt as they allow for the democratisation of education and the positive return on wellbeing that this bringsnot only does Pinker suggest that more education "really does make countries richer" (2018, p. 234) but he also claims that "educated people ... are less racist, sexist, xenophobic, homophobic and authoritarian" (2018, p. 235). Secondly, there is also, according to Pinker, an indirect benefit to these technologies: with a more educated populace comes the potential to create advanced technologies-AI, distributed manufacturing equipment and techniques, genetic engineering, etc.- - which then can be applied to solve humanity's maladies (2018, pp. 330-333): genetic modification can alleviate food scarcity through causing greater yields on crops, AI could help to design bespoke treatments to disease, and so on (2018, p. 331ff). Such technology driven progress, Pinker suggests, has already made us healthier, safer, smarter, more peaceful and prosperous (Pinker et al., 2016, pp. 6-8) and will also "only accelerate" (2016, p. 9) as our technological capacities continue to grow ${ }^{1}$.

Pinker's claim that progress in improving the human condition is owed to the expansion of our technological capacities presents a problem to any influence that philosophy would wish to exert on the development of future technologies. Technology, to Pinker, is the driving force of progress, without which significant improvement in human wellbeing would likely not have arisen - the image of technology presented by Pinker is one of an unqualified social good. Such an image hinders Philosophy's potential influence over technological change by encouraging technological theorists to take up an optimistic and uncritical attitude towards technology. By establishing and stressing a link between technology and human wellbeing, the idea of progress acts to discourage potential critics of technology. Under the auspices of progress, technology becomes more than technique or device, rather it becomes that which allows us to escape our condition of brutishness and thus, valid criticisms are in danger of being lost to optimism.

\footnotetext{
1 Though Pinker is a staunch technological optimist, he is aware of the arguments of those who do not share this position (See Pinker, 2018, pp. 32-33). Pinker dismisses such views as "declinism" (2018, p. 33) caused by the "nature of news [which] is likely to distort people's view of the world" (2018, p. 41). Technological pessimism, to Pinker, is a consequence of frequently pessimistic media coverage of events which obscure the build-up of human progress over long periods of time.
} 


\section{Decoupling technology and progress}

If we are to prevent optimism from colouring our view of technology, we must demonstrate that Pinker's suggested link between technological progress and increased human wellbeing is mistaken. Pinker is keen to ground his argument in objective statistics, claiming that "the only way to understand the fate of the world is with facts and numbers, to plot the incidence of good things and bad things over time" (Pinker et al., 2016, p. 6). Such an approach allows Pinker to draw the conclusion that the wellbeing of an average person, spurred on by burgeoning technological development, has improved significantly over time. Consider the following:

But are we any happier? If we have a shred of cosmic gratitude, we ought to be. An American in 2015, compared to his or her counterpart a half-century earlier, will live nine years longer, have had three more years of education, earn an additional $\$ 33000$ a year per family member [. . . ] and have an additional eight hours a week of leisure (Pinker, 2018, p.262).

From this we can see that Pinker's argument operates by identifying a series of markers of well-being-life expectancy, length in education, material wealth, and leisure-and linking a quantitative increase of these markers to a qualitative increase in human wellbeing. Here there is a flaw in Pinker's reasoning - to be convinced of Pinker's position, one must first hold the opinion that the markers of well-being chosen by Pinker are themselves desirable, yet the universal desirability of these markers is not a given. Desirability is a judgement of a situation, not the metaphysical condition of a statistical rise, and thus Pinker's treatment of these markers as universally desirable is a misrepresentation of their subjective nature. Indeed, this is an issue seen elsewhere in Pinker's rationale.

Pinker argues that the statistical increases in the markers of wellbeing translates into an increase in happiness through taking "a closer look at the facts about human happiness" (2018, p. 262). Yet again, it seems that Pinker is guilty of the same category error. Human happiness and wellbeing is an individual subjective phenomenon, and as such it resists proper expression in general facts and statistics about a population. Because of the subjective nature of wellbeing, the articulation of a standardised metric of happiness is impossible, and thus, Pinker must rely on maladies that appear to coaccompany a lack of well-being to evidence his claims: the reported incidences of loneliness and rates of suicide (2018, pp. 274-280). This is problematic as suicide and loneliness are not sufficiently reliable indicators of wellbeing. One can have a dearth of wellbeing without contributing to either of these indicators: misery need not be so intense as to take one's own life, and loneliness is only one of many sources of human suffering. Therefore both seem to be poor markers of overall human wellbeing-indeed, it is logically possible for a net decrease in wellbeing to take place concurrently to falling suicide rates and diminishing reports of loneliness, and as such, Pinker's argument that overall happiness has increased is a conclusion that is underdetermined by the data that supposedly supports it.

Highlighting that the increase in technological capabilities has done little to encourage rationality and humanism, and indeed may well precipitate a decline in wellbeing also acts to undermine the purported link between wellbeing and technology. John Gray argues that 
the Enlightenment idea that a rational humanism is the product of technological development is incorrect. According to Gray, "once a new technology is out in the world anyone can use it" (Gray, 2004, p. 21), and "technologies can give a new lease of life to the side of human nature that is not and will never be rational" (2004, p. 18). Consider Gray's examples of "the Taliban commander directing military operations from his cellular telephone" (2004, p. 18), or the "proliferation of weapons of mass destruction" (2004, p. 21) that characterised the height of the Cold War. Such examples demonstrate that an irrational deployment of technology is possible and thus highlight the mythological nature of technology-driven progress. Moreover, these examples also act to show how technologies can act to diminish wellbeing. The proliferation of weapons of mass destruction, for example, brings with it an existential anxiety that would not exist otherwise, and the existence of terroristic forces empowered by technology has led to the development of wide-scale (and, notably, technology driven) surveillance and an erosion of civil liberties (Zuboff, 2019, pp. 112-115). This, in combination with the flaws in Pinker's argument, is sufficient to undermine the supposed link between technology and progress. Gray's examples evidence that technology is not a necessarily beneficial influence on human wellbeing, and show to us that technology, in part, is a tool that can be utilised to realise ends of diverse values-not only can technology bolster wellbeing, but it can also act to its detriment. With this in mind, one can reckon with an accurate view of technology—not one that is distorted by optimism—and this is of vital importance if philosophy wishes to exert influence over technology's future. Too keen a focus on the benefits of technology means that we risk becoming blind to its negative ramifications thus undermining the ability to enact effectual and meaningful influence over technological change.

\section{Technological determinism as a barrier to influence}

A second myth also hampers philosophy's influence over technological change: technological determinism. Technological determinism can be thought of as the synthesis of the idea that "technical progress follows a unilinear course [. . .] from less to more advanced configurations" (Feenberg, 2010, p. 8) with the claim that "social institutions must adapt to the "imperatives" of the technological base" $(2010$, p. 9). Thus technology is presented as the "decontextualized, self-generating [. . .] foundation of modern society (2010, p. 9), free from influence from the society that it shapes: "technical progress is an exogenous force influencing society rather than an expression of changes in culture and values" $(2010$, p. 8). It is difficult to see how philosophy could exercise any influence over the development of future technologies whilst such a conception of technology is commonly held as such a conception envisages any attempt to guide the progression of technological change as futile.Technological determinism is lent significant authority by Martin Heidegger's influential critique of technology. Heidegger suggests that the true essence of technology is masked by two common understandings of technology (Heidegger, 1954, p. 312ff) — the anthropological understanding that takes technology to be a kind of human behaviour, and the instrumental understanding, where technology is a "means to end" (1954, p. 312ff). For Heidegger, these understandings prevent us from recognising that technology is also "a way of revealing" (1954, p. 318). Aside from augmenting our practical capacities, technology also acts to influence the way in which 
we interpret the world. Such influence-enframing-is, to Heidegger, the true essence of technology. Enframing operates by way of influencing what shows up for us as usefulonce technologies are deployed to a society, they articulate a set of imperatives, thereby "challeng[ing]-forth" (1954, p. 335) a particular interpretation of the world.

Heidegger warns that so long as enframing operates, technology will diminish humanity's role in interpreting the world. For Heidegger, enframing threatens to strip interpretive diversity from the world and replace it with a single unified understanding: "modern technology starts man upon the way of revealing through which the actual everywhere, more or less distinctly, becomes standing reserve" (1954, p. 329). Heidegger warns that all—even humanity itself-will becomes levelled-down to the status of standingreserve. Through responding to the imperatives articulated by technology, humanity becomes beholden to that technology, and thus, levelling-down will, according to Heidegger, reach a stage "where [man] himself will have to be taken as standing reserve" $(1954$, p. 332). Once this occurs, humanity, and their societies, will cease to be self-defining. What a human is, and thus the position in their society, will become an expression of the technologies deployed to their societies. Such a situation, where mankind loses "his relation to himself" (1954, p. 332), is characterised by the inability to recognise that we are responsible for interpreting our worlds and a blindness to other potentialities of existence and other social configurations. Our hermeneutic capacities are superseded by those technologies and influence over technological change in general is lost alongside our ability to reckon with other possibilities_influence becomes impossible because we lose the capacity to see things in any other way than they already are.

\section{Marcuse, rationality and technology}

For Marcuse, the image of technology as an autonomous force that acts to inform the configuration of our societies is inaccurate. According to Marcuse, such an image is an aberration that arises due to neglecting the concrete situations from which technologies are developed and deployed. Marcuse argues that the "march of technology" (Marcuse, 1941, p. 42) was initiated as a consequence of the "various religious, political and economic tendencies which shaped the idea of the individual in the sixteenth and seventeenth century" (1941, p. 42). Such tendencies precipitated a notion of the individual as in possession of a set of values that "no external authority was supposed to encroach upon" (1941, p. 42): it is the role of the individual to articulate, pursue and actualise the "forms of life" (1941, p. 42) that allow for the realisation of their capacities and capabilities. This pursuit of selfinterest, according to Marcuse, drove the mass deployment of technologies to society-a deployment that caused a shift in the rationality of that society: "individualistic rationality has been transformed into technological rationality" (1941, p. 44). Whereas the rationality of the proto-technological society was characterised by self-interest, this shifted once the technologies were deployed-self-interest became superseded by an adherence to the "dictates of the apparatus" (1941, p. 44).

Here, Marcuse's exposition exhibits some similarities to technological determinismboth agree that the technologies present in a society influence its configuration by mandating a particular interpretation of the world-but it is also here where the 
distinction between the two positions is at its most keen. Marcuse presents a view of technology counter to that advanced by Heidegger-technology is not autonomous and decontextualized, but rather it is necessarily rooted within a particular historical and social context. Technology is "always a historical-social project" (Marcuse, 1965, p. 168): it is, to Marcuse, a manifestation of "what a society and its ruling interests intend to do with men and things" (1965, p. 168). Technology therefore, becomes a site of political manipulation and thus a locus of political power. By encouraging the uptake of arbitrary social values, via the deployment of technologies that proscribe the relevant dictates to a society, such technologies become an expression of political will: "political power asserts itself through its power over the machine process and the ... organisation of the apparatus" (Marcuse, 1964, p. 5). For Marcuse, the neglect of this key historical-social aspect of technology causes the technological determinist to express a distorted image of technology. In its place, Marcuse presents a conception of technology that sits in a dialectical relationship to society: technology is developed in response to an already-existing social rationality, in order to allow a possible social rationality-one that is sympathetic to the wishes of societal powers-to be realised. By neglecting this aspect of technology, the myth of technological determinism "remove[s technologies] from the context of power relations in which they are constituted and which determine their use and function" (Marcuse, 1977, p. 168), and thus presents an incomplete analysis; the dialectic relationship between society and technology, where each influences the other, is misrepresented as a relationship characterised by unilateral influence, of technology on society. Technologies are thus erroneously "reified ... as fate" (1977, p. 168), and the ability for societal actors to exert influence upon their development is obscured-should philosophy wish to establish influence over the development of future technology, it must treat the myth of technological determinism with scepticism in order to guarantee itself the conceptual space necessary for it to realise such a role.

\section{A potential method of influence}

Once the myths of progress and technological determinism have been undermined, the conceptual barriers hindering philosophy's potential influence over technological development have been removed-although, the question of how philosophy can realise its potential remains to be settled. It is clear that the influence of philosophy over the development of technology would be at its most simple, if those who were at the frontline of technological development were equipped with a philosophical education so its influence could be felt first-hand. But this kind of influence is perhaps inefficient, as its directness mandates the presence of a philosopher on each team realising some technological project, at least, should philosophy wish its influence to be substantial. Moreover, in the context of the danger presented to us by technologies, such a localised influence may be undesirable as the magnitude of such problems necessitates wide-spread action, and thus, a method of influence capable of being scaled up would be more valuable.

We have thus far briefly touched upon two dangers that technology poses to humanityan existential danger, touched upon by Gray and a hermeneutic danger, articulated by Heidegger. These dangers have also been echoed by Hans Jonas (1979) and Luciano Floridi 
(2013) respectively. Jonas is keen to stress that that "modern technology [. . .] has enhanced human power beyond anything known or even dreamed of before [ . . . a power over matter, over life on earth, and over man himself" (Jonas, 1979, ix) and thus now has the ability to cause such profound ecological degradation to make continued human life on earth unviable. Floridi warns that Information and Communications Technologies are warping our sense of personal identity by both digitally preserving externalised self-defining memories, thus limiting our capacity for online self-redefinition (Floridi, 2013, p. 223) and by supplying us with an amplified and prolonged digital gaze, allowing us the ability to "[see] oneself as seen by others" (2013, p. 224), but from a position "constrained by the nature of the medium" (2013, p. 225), thereby causing a distorted image of our selfhood, that can then negatively impact our self-understanding. Both Jonas and Floridi recommend that these dangers should be mitigated through the intervention of ethics in the design and deployment of technologies, a suggestion that offers philosophy a potentially valuable method of influence-the formulation of robust ethical maxims to guide technological change ${ }^{2}$.

The articulation of ethical maxims, in isolation, may not be enough for philosophy to influence technological development in a meaningful way. As Floridi suggests, attention must be paid as to "how ethics can be effectively and successfully applied and implemented [...] to make a positive difference" (Floridi, 2019, p. 185), in order to prevent the translation of "principles into practice [. . . be[ing] undermined by some ethical risks" (2019, pp. 185186). Floridi continues by demonstrating the kind of influential oversight that philosophy is best placed to provide: the identification of these ethical risks and suggestions as to how they may be mitigated. Floridi gives examples of several of the kind of practices that may be used to escape proper ethical regulation-from the cherry-picking of ethical guidelines, either by selecting and combining principles from several ethical systems to make a bespoke system that lacks the rigour of the originals $(2019$, p. 186) or by moving the base of one's operations to a locale with less stringent ethical requirements (2019, pp. 189-190) to dishonesty about one's ethical compliance through implementing only superficial measures $(2019$, p. 187) or by claiming one's compliance whilst shirking the duties that it entails (2019, p. 191). By doing this, Floridi offers a powerful blueprint of how philosophy can maximise its potential influence over technological change; first by helping to shape the ethical guidelines that the actors must follow, and then secondly, ensuring that the spirit of the guidelines is complied with through supervision of their implementation. Though such a method of influence is contingent on factors external to philosophy-for instance, the existence of a willing and responsive regulatory body that can ensure compliance with such regulations-ingratiating

\footnotetext{
2 There is a temptation here to fall back on traditional ethical systems as a guide for the articulation of such maxims, though it does not seem prudent to assume that they are directly applicable to the novel and diverse challenges presented to us by technology. For instance, many of the most pressing dangers presented to us are necessarily future-orientated-ecological degradation, for example, carries an intergenerational risk - and as such the "present oriented character" (Jonas, 1979, p. 12) of traditional ethical systems leaves them ill-equipped to deal with such problems. Similarly, new technologies bring with them threats that are indeed present orientated, but that are sufficiently novel to be a poor fit for standing ethical systems. As such, a bespoke technological ethics, perhaps one grounded in the conceptual foundations of Floridi's Computer and Information Ethics (found in Floridi, 2013, Ch. 1-5), may be the best way to meet the challenges of a rapidly developing technological landscape.
} 
itself into the regulatory processes seems to be perhaps the most valuable method of exerting influence over future technological change available to philosophy ${ }^{3}$. But before it can take up such a role effectively, it must be alert to the dangers that the kinds of mythological thinking discussed earlier in this piece present—with such thinking comes a distorted image of technology which risks undermining the lucidity and effectiveness of any of philosophy's guidance.

\section{Conclusion}

In this paper I have argued that, in order to have influence over technological development, philosophy must see beyond the myths of progress and technological determinism, and focus its efforts on articulating ethical maxims and supervising their translation into real world settings. The progressive view, that technology is the driving force behind increases in human wellbeing, it was argued, impedes philosophical influence by encouraging a unjustified optimism, and the technological determinist's view that technology is replete with an autonomous logic was argued to impede influence upon its development by presenting any attempt to exert such an influence as futile. As suggested by Gray and Marcuse, respectively, each myth is drawn from an incomplete understanding of technology-the progressive neglects the potential costs on wellbeing caused by technology, and the determinist neglects the socio-political character of technology. Finally, I have argued that the dangers of technology mandate a method of influence capable of widespread deployment, drawing upon Jonas' and Floridi's call for ethical intervention in the design and delivery of technology to ground my suggestion that philosophy's influence is best achieved through the articulation of robust ethical maxims and supervision over their translation into practice.

Philosophy's familiarity with deep and methodical thinking suggests that it would be a valuable complement to the expertise of those directly responsible for ongoing technological development. The influence of philosophy could help to minimise the risk that the dangers of technology are realised, and it could offer valuable insight into mitigating any issues that do arise, but it is only through the demythologisation of its thinking, and focussing its efforts on exerting its influence most effectively, that philosophy can take up this role.

\section{References}

Feenberg, A. (2010). Between reason and experience: Essays in technology and modernity. Cambridge, MA: MIT Press.

Floridi, L. (2013). The ethics of information. Oxford: Oxford University Press.

Floridi, L. (2019). Translating principles into practices of digital ethics: Five risks of being unethical. Philosophy \& Technology, 32(2), 185-193.

Gray, J. (2004). Heresies: Against progress and other illusions. London: Granta.

\footnotetext{
3 Indeed, by doing so philosophy may also begin to influence the social background that, as Marcuse suggests, informs the character of our technologies - should such a situation arise, philosophy's influence over technology could be amplified across many societal iterations. Ethical oversight over technologies could produce a more ethical society, which in turn would produce even more ethical forms of technologies in the future.
} 
Heidegger, M. (1954). The question concerning technology. (W. Lovitt, Trans., from German in 1977). In D. F. Krell (Ed.), Basic Writings: Revised and expanded edition (1992). Oxford: Routledge.

Jonas, H. (1979). The imperative of responsibility. In search of an ethics for the technological age. (H. Jonas \& D. Herr, Trans., from German in 1984). Chicago, IL: University of Chicago Press.

Marcuse, H. (1941). Some implications of modern technology. In D. Kellner (Ed.), Technology, War and Fascism: Collected Papers of Herbert Marcuse, Volume One (2004). New York: Routledge.

Marcuse, H. (1964/2002). One-Dimensional man ( $2^{\text {nd }}$ ed.). Oxford: Routledge.

Marcuse, H. (1965). Industrialization and capitalism in the work of Max Weber. (J. J. Shapiro, Trans., from German). In Negations: Essays in critical theory (2009). London: Mayfly.

Marcuse, H. (1977). Heidegger's politics: An interview. In R. Wolin \& J. Abromeit (Eds.), Heideggerian Marxism (2005). Lincoln, NB: University of Nebraska Press.

Pinker, S., Ridley, M., de Botton, A., \& Gladwell, M. (2016). Do humankind's best days lie ahead? London: Oneworld.

Pinker, S. (2018). Enlightenment now: The case for reason, science, humanism and progress. London: Allen Lane.

Zuboff, S. (2019). The age of surveillance capitalism: The fight for a human future at the new frontier of power. London, Profile Books.

School of Social, Political and Global Studies

Keele University

Keele

Staffordshire

ST5 5BG

United Kingdom

Email: k.m.brayford@keele.ac.uk 